\title{
The epidemiology of golf-related injuries in Australian amateur golfers - a multivariate analysis
}

\author{
A McHardy (BMedSc, MChiro, GradDipChiro (Paed), PhD (Cand)) ${ }^{1}$ \\ H Pollard (BSc, GradDC, GradDipAppSc, MSportsSc, PhD) ${ }^{1}$ \\ K Luo (BEng, MAppIStat, PhD) ${ }^{2}$ \\ ${ }^{1}$ Macquarie Injury Management Group, Department of Health and Chiropractic, Macquarie University, Sydney, Australia \\ ${ }^{2}$ Department of Statistics, Macquarie University, Sydney, Australia
}

\begin{abstract}
Objective. To perform an epidemiological study in order to determine the golf-related injury locations, injury rates and possible risk factors for golf injury in amateur golfers across Australia.
\end{abstract}

Method. A retrospective cross-sectional survey of Australian golf club members was used to collect data for the study. Chi-square testing was used to evaluate the association between golf injury and each possible risk factor at univariate level. All the possible risk factors were further examined in multivariate analysis using logistical regression.

Results. There were 1634 golfers included in the present study. Of these, 288 reported having had one or more golfrelated injuries in the previous year. The most common injury location was the lower back $(25.3 \%)$, followed by the elbow $(15.3 \%)$ and shoulder $(9.4 \%)$. The most common injury mechanism was poor technique in execution of the golf swing (44.8\%). Age, warm-up status, conditioning habits, wearing a golf glove/s and injury acquired in other sports / activities were significantly associated with risk of golf injury $(p<0.05)$. Equipment use such as type of golf club shaft used, type of shoes used and other factors studied were not statistically significant.

Conclusion. The most injured sites identified in this study were the lower back, elbow and shoulder respectively. Risk of injury during golfing varied according to age group, warm-up status, conditioning habits, whether the player wore a golf glove/s, and whether the golfer had been injured in other activities.

\section{CORRESPONDENCE:}

A McHardy

PO Box 448

Cronulla NSW 2230

Australia

E-mail: golfinjury@optusnet.com.au

\section{Introduction}

Golf is a popular sport played worldwide by people of all ages and skill levels. Part of the appeal of golf is that there are no gender, skill or age limits to participation. Golf participation rates vary across all age ranges and are high in the older age groups. This is partly due to the fact that those in the older/retired population have more leisure time to pursue activities and the fact that golf is low impact with a general aerobic component, which makes it a perfect recommendation for practitioners wanting their patients to exercise. Golf is a popular option as it also provides social interaction and can be played at all skill levels due to its handicap system. Additionally, for those people who like to remain active and competitive as they age, golf is a popular option.

Although uncommon, injuries do occur whilst playing golf. Considering the popularity of golf, both in terms of participation and spectator rates, it is surprising that there have been only a few small studies on golf injury. Gosheger et al. ${ }^{8}$ reported that most of our understanding of golf injuries relies on two publications produced by McCarroll et al. ${ }^{13}$ in 1990 and Batt in $1992,{ }^{4}$ and one produced over 20 years ago by McCarroll and Gioe. ${ }^{14}$ The aims of this study were to determine the golf-related injury locations among amateur golfers across Australia, to examine the common injury mechanisms in golf, and to determine if factors such as age, gender and skill level affect injury rates. As golf-related injury occurs frequently in the golf swing, this study also attempted to ascertain the golf swing phase during which most injuries occur.

\section{Methods}

\section{Survey design}

A survey questionnaire comprising 53 questions was developed to collect data for the study. Information was collected on age, gender, skill level, level of self-rated golfing importance, play/practice habits, type of warm-up and conditioning habits, golf-related injury in the previous 12 months, tuition, mode of club transport, and age and cost of equipment. For the purpose of this study, a golf-related injury was defined as any condition sustained during the playing/practising of golf that stopped play/practice, impeded normal performance or required medical treatment including over-the-counter medication such as analgesics, non-steroidal anti-inflammatories 

or liniments. As such, an injury was recorded if any of the three criteria were applicable.

Golfers who had sustained an injury in the past 12 months were asked further questions, including questions on injury onset, injury mechanism, previous history of injury, and whether treatment was sought after injury. Ethics approval for this study was obtained through Macquarie University. An envelope containing a cover letter stating the purpose of the study, an information/consent form, the survey and a reply-paid envelope was mailed to each member of golf clubs agreeing to participate in the study.

\section{Statistical analysis}

Each factor (e.g. age, skill level, gender, etc.) was first examined in relation to risk of golf-related injury (i.e. injury of any body site) in the univariate analysis. Chi-square testing and contingency tables were used to evaluate the association between golf-related injury status, injured vs. non-injured, and each possible risk factor studied at the univariate level. Factors that appeared to be important in the univariate analyses were further examined in multivariate analysis using logistical regression. ${ }^{11}$ Odds ratios and $95 \%$ confidence intervals were used to measure the strength of association between each risk factor studied, and injury. An odds ratio of 1 meant no association, i.e. the two groups compared had a similar risk of injury. If a $95 \%$ confidence interval did not contain the value of 1 , this indicated that there was a statistically significant association between the risk factor studied and injury (less than 1 being a reduction in risk and greater than 1 an increased risk of injury). Statistical analyses in the study were performed using the statistical software package SPSS (SPSS Inc. Chicago, Illinois, USA), with a significance level of $5 \%$. To determine how representative the respondents were of the Australian golfing population, national handicap and male-to-female golfer distribution were compared with the data for respondents in this study. ${ }^{2,3}$

\section{Results}

One thousand six hundred and thirty-four amateur golf players returned their survey forms from 10 clubs in Australia (7 813 sent, response rate $21 \%$ ). The average age of the 1634 golfers was $55.2 \pm 14.6$ years. There were 318 females $(19.5 \%)$ with an average age of $59.2 \pm 12.2$ years, and 1316 males (80.5\%) with an average age of 54.3 \pm 15.3 years. The average handicap of female respondents was $26.3 \pm 9.5$, and of male respondents $18.1 \pm$ 7.0. Respondents reported that golf scored 7.4 out of 10 $( \pm 1.9)$ in importance on a visual analogue scale (VAS) ( 1 being not important, 10 being very important). A total of 288 golfers reported sustaining at least 1 injury in the past year. Results analysing the 288 primary injuries were reported. The injury rates of men and women were the same (17.6\%).

In total, 73 golfers reported having sustained an injury to the lower back region $(25.3 \%)$. In this cohort, the lower back was the most common injury site followed by the elbow
(15.3\%) and the shoulder (9.4\%) (Fig. 1). The most common mechanism of injury reported by golfers was a self-reported incorrect golf swing (44.8\%), followed by overuse $(25.3 \%)$ (Fig. 2).

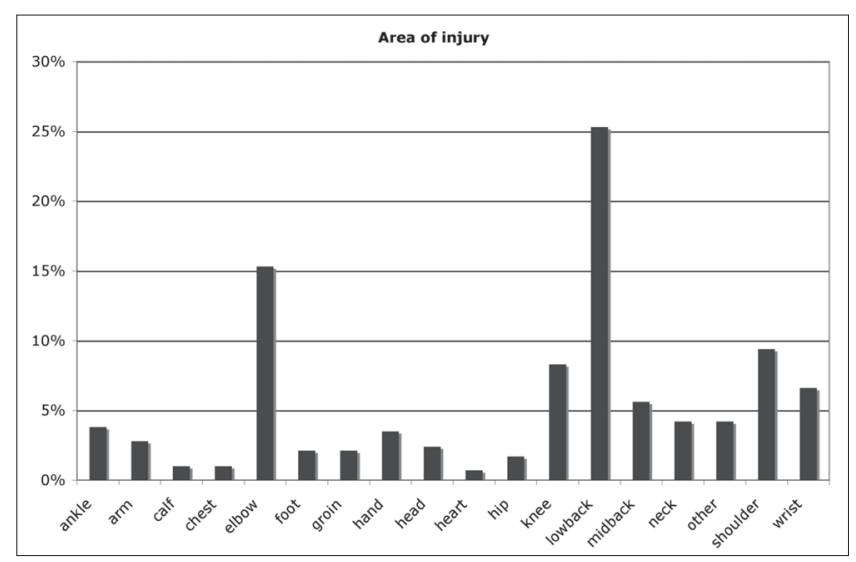

Fig. 1. Reported sites of golf injury $(N=288)$ in the previous 12 months.

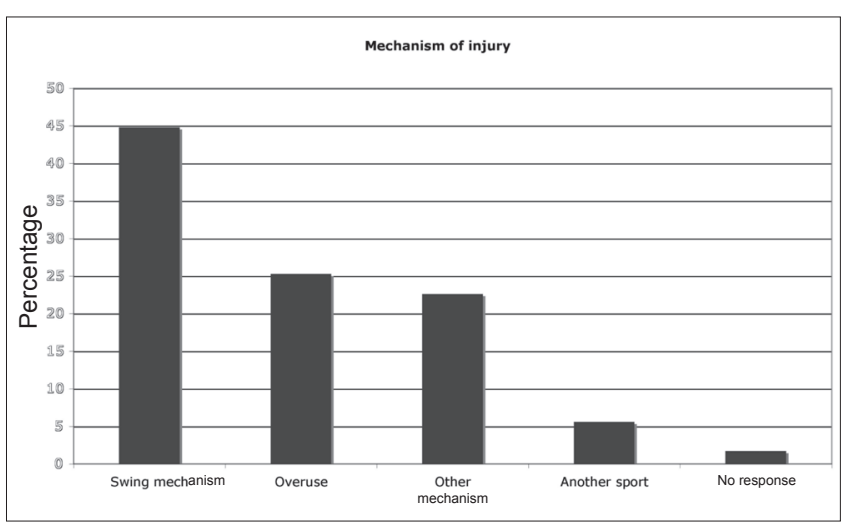

Fig. 2. Mechanism of injury in golfers.

Regarding where in the golf swing the respondent felt that the injury occurred (Fig. 3), 30.2\% said the follow-through and $17.7 \%$ the downswing. Those golfers who indicated 'other' in response to the question reported that more than 1 swing phase or specified impact and/or hitting the ground caused their injury, with impact-based injury accounting for $20 \%$ of all responses in the 'other' category and $6 \%$ of the overall injured golfers. A total of $57.3 \%$ of golfers who sustained an injury reported that the injury occurred over a period of time, while $46.9 \%$ of those who sustained injury reported having had a previous injury at the same injury site. Golf was reported to have aggravated the injury in $72.2 \%$ of cases, while the injury was not aggravated by any activity in $14.9 \%$ of cases.

Almost $75 \%$ (74.7\%) of those injured reported having sought treatment for their injury. Of the practitioners sought, physiotherapists were sought most often (47.4\%), followed by general practitioners $(47.0 \%)$ and chiropractors $(27.9 \%)$ (Fig. 4).

Of the injured golfers, $4.9 \%$ reported to have stopped practising, $5.2 \%$ reported to have stopped playing, and $55.2 \%$ 


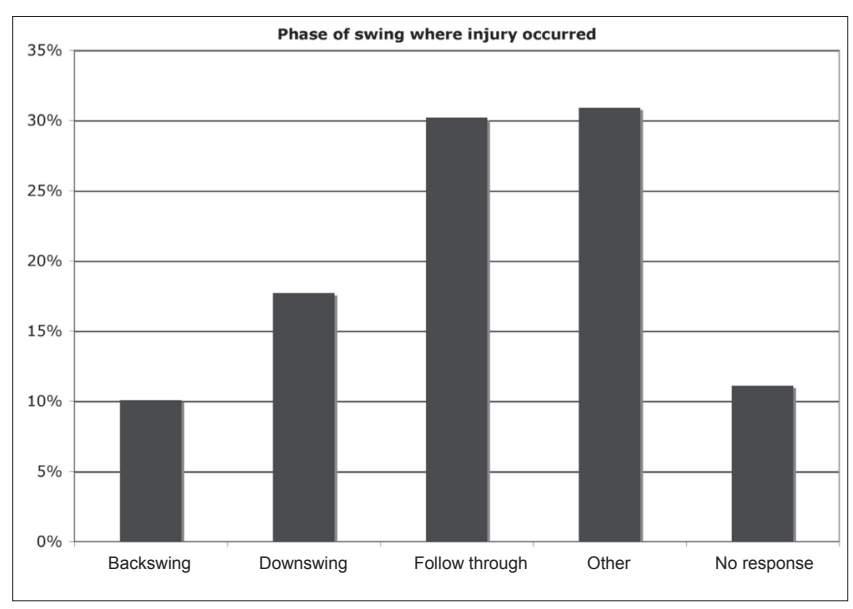

Fig. 3. Responses to the question 'in what phase of the golf swing did the injury occur?' (No response $N=32$, backswing $N=29$, downswing $N=51$, follow-through $N=$ 87 , other $N=89$, of which 18 at impact).

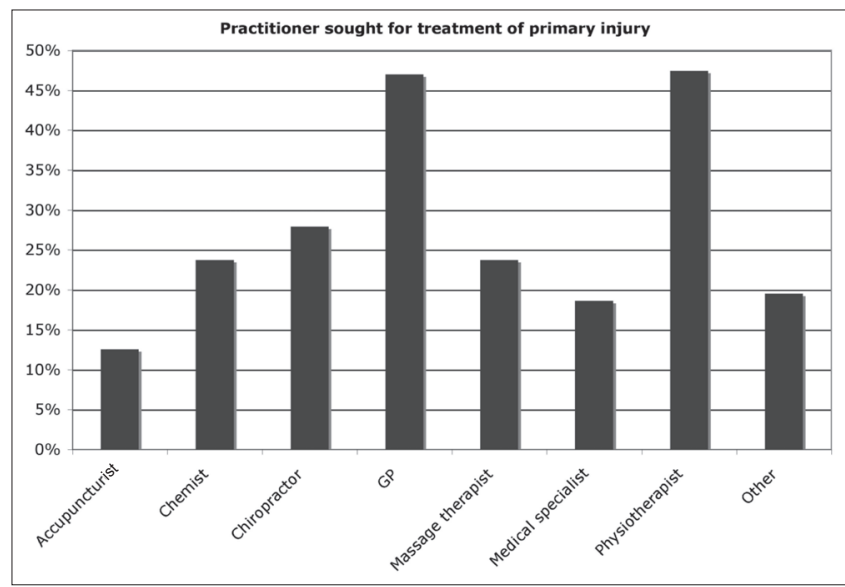

Fig. 4. Practitioners sought by those who sustained an injury.

reported to have stopped both play and practice (Table I). The most common length of time off practice was 2 - 3 weeks, followed by 1 - 2 weeks, while $14.5 \%$ reported having spent more than 12 weeks off practice following the injury (Fig. 5).

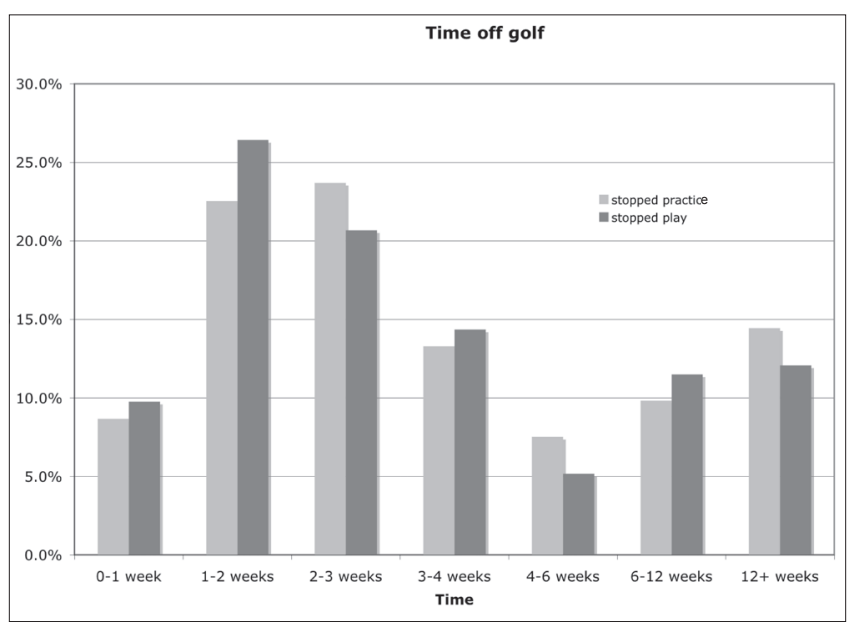

Fig. 5. Time off reported by those golfers who stopped golf play / practice as a result of injury $(N=188)$.
TABLE I. Distribution of responses to the survey question 'Did your injury stop you playing / practising golf?'

\begin{tabular}{lll}
\hline & \multicolumn{2}{l}{ Injured players } \\
\cline { 2 - 3 } & $\%$ & $\mathbf{N}$ \\
\hline Stopped practice only & 4.9 & 14 \\
Stopped playing only & 5.2 & 15 \\
Stopped both practice and play & 55.2 & 159 \\
Did not stop me & 32.3 & 93 \\
No response & 2.4 & 7 \\
& 100.0 & 288 \\
\hline
\end{tabular}

The most common length of time off from golf play was 1 - 2 weeks, followed by 2 - 3 weeks, while $12.1 \%$ reported having spent more than 12 weeks off practice following the injury (Fig. 5).

Those variables that appeared significant in univariate analysis are presented in Table II. Results showed that age, other sports / activities, golf club shafts used, glove use, golf shoe use, warm-up and conditioning habits and game I practice habits appeared significant. Using multivariate analysis, these factors were further examined in relation to the risk of golf injury.

The results including odds ratios and the corresponding $95 \%$ confidence intervals obtained from the multivariate analysis are presented in Table III. It was found that age remained significant after adjusting for all other factors in the multivariate analysis. Golfers aged above 40 years had the highest risk: 40 - 59 years (OR 5.7, 95\% Cl: 2.0 - 16.0), 60 - 69 years (OR 5.4, 95\% Cl: 1.9 - 15.6), and 70+ years (OR $4.4,95 \% \mathrm{Cl}: 1.4-13.1)$, followed by those aged between 20 and 39 (OR $3.8,95 \% \mathrm{Cl}: 1.1$ - 13.6), while the youngest group (under 20) had the lowest risk of injury. Golfers who reported sustaining an injury in other sports or activity in the previous 12 months were more likely to have reported a golfrelated injury in the same period (OR 2.2, 95\% Cl: $1.6-3.1$ ).

After adjusting for the other 2 warm-up variables (air swings, hitting balls), only range of motion exercises remained significant, showing a positive association with the risk of injury (OR 1.6, 95\% Cl: 1.2 - 2.2). For conditioning activities, only golf-related strength work significantly increased risk of injury (OR 2.7, 95\% Cl: 1.6 - 4.6). Golf-specific stretching during the week was no longer significant after adjusting for golf practice activities, and general stretching and strength work were no longer significant after adjusting for golfspecific stretching and strength work in the same model. After adjusting for other golf practices, golf practices including chip-putt $(p=0.2)$, full shot $(p=0.4)$ and game play $(p=0.1)$ were no longer significant. The type of club shafts used by golfers was not significantly associated with injury $(p=0.05)$, although using steel irons / graphite woods or all graphite exhibited a greater risk of injury than all-steel shafts (OR 1.8, 95\% Cl: 1.2 - 2.6 and OR 1.6, 95\% Cl: 1.0 - 2.4 respectively). Wearing golf gloves was associated with increased risk of injury compared with using no glove (left hand $p=0.02,95 \%$ 
TABLE II. Summary of variables considered in multivariate analysis

\begin{tabular}{|c|c|c|}
\hline Variable & \multicolumn{2}{|c|}{ Categories analysed } \\
\hline \multirow[t]{6}{*}{ Age } & \multicolumn{2}{|l|}{$0-20$} \\
\hline & \multicolumn{2}{|l|}{$20-29$} \\
\hline & \multicolumn{2}{|l|}{$30-39$} \\
\hline & \multicolumn{2}{|l|}{$40-59$} \\
\hline & \multicolumn{2}{|l|}{$60-69$} \\
\hline & \multicolumn{2}{|l|}{$70+$} \\
\hline \multirow[t]{2}{*}{ Other sports / activities } & \multicolumn{2}{|l|}{ Yes } \\
\hline & \multicolumn{2}{|l|}{ No } \\
\hline \multirow[t]{4}{*}{ Club shafts } & \multicolumn{2}{|l|}{ All steel } \\
\hline & \multicolumn{2}{|c|}{ Steel irons/graphite woods } \\
\hline & \multicolumn{2}{|l|}{ All graphite } \\
\hline & \multicolumn{2}{|c|}{ Graphite irons/steel woods } \\
\hline \multirow[t]{5}{*}{ Wear golf shoes } & \multicolumn{2}{|l|}{ No } \\
\hline & \multicolumn{2}{|l|}{ Yes/plastic spikes } \\
\hline & \multicolumn{2}{|l|}{ Yes/rubber ripples } \\
\hline & \multicolumn{2}{|l|}{ Yes/metal spikes } \\
\hline & \multicolumn{2}{|l|}{ No response } \\
\hline \multirow[t]{4}{*}{ Glove use } & \multicolumn{2}{|l|}{ No } \\
\hline & \multicolumn{2}{|l|}{ Yes left hand } \\
\hline & \multicolumn{2}{|l|}{ Yes right hand } \\
\hline & \multicolumn{2}{|l|}{ Yes both hands } \\
\hline Warm-up habits & No & \\
\hline & Warm up & \\
\hline & Air swing & \\
\hline & Hit balls & \\
\hline Conditioning habits & No & \\
\hline & General stretching & \\
\hline & Golf-specific stretc & \\
\hline & General strengther & \\
\hline & Golf-specific stren & ening \\
\hline Game / practice habits & Chipping / putting & $0-1$ \\
\hline & & $1+$ \\
\hline & Full shot & $0-1$ \\
\hline & & $1-2$ \\
\hline & & $2-3$ \\
\hline & & $3+$ \\
\hline & Game play & $0-9$ holes \\
\hline & & $1-2$ rounds \\
\hline & & 3 rounds \\
\hline & & $4+$ rounds \\
\hline
\end{tabular}

$\mathrm{Cl}: 1.2-2.5$, both hands $p=0.00 .95 \% \mathrm{Cl}: 2.3-11.7)$. In contrast, those who wore golf shoes with rubber ripples had significantly lower risk of injury compared with those wearing no golf shoes ( $p=0.02,95 \% \mathrm{Cl}: 0.2-0.9)$.

\section{Discussion}

The golf literature suggests that the 3 most common injury sites are the lower back, elbow and wrist, with the shoulder as the fourth most common injury site. ${ }^{4,13,14}$ This study agreed with the literature that the lower back was the most common site of golf injury, followed by the elbow, but the shoulder was injured more often than the wrist in this sample. Potential reasons for the differences between the results of this study and the literature include that the sample size of previous studies was small. Additionally, there was greater potential for recall bias in golfers sampled in the previous studies requiring information on injuries over a whole golfing career, rather than just in the previous year, as in this study. ${ }^{15}$ The chance of recall bias increases with increased recall period. ${ }^{22}$

The most common injury mechanism found in this study was poor technique in the execution of the golf swing (aberrant mechanics), which is in agreement with the findings in the literature. $^{4,13,14}$ The amateur golfer is more likely to have an aberrant swing pattern that could predispose to injury at a rate potentially greater than that of the professional golfer. ${ }^{10}$ Most golf injuries reported in this study occurred in the golf swing. To ascertain the golf swing phase where most injuries occurred, the swing was divided into several well-defined phases including backswing, downswing and follow-through. Golfers who reported that they were injured 'at impact', formed a separate category ('other') together with those reported as injured in ways other than the three phases defined above. According to the literature, the follow-through phase is the most common phase in which injury occurs. ${ }^{4,13,14}$ This phase occurs at the end of the swing, after the ball has been hit and the body is slowing in movement. This phase is associated with the eccentric action of the trunk rotators ${ }^{16,20}$ and lumbar hyperextension depending on the golf swing type. ${ }^{17}$ Further study is required with regard to the influence of the golf swing on injury occurrence, particularly the follow-through phase.

As shown in this study, a large proportion of injured golfers sought treatment with allied health practitioners such as physiotherapists, chiropractors, and massage therapists. This implies that hospital admission-based injury epidemiology studies, where hospital records are analysed for golf-related injury, are unlikely to reflect the actual occurrence of golfrelated injury and would be skewed to more serious injury. This observation was also made by Fradkin and co-workers. ${ }^{7}$

The present study also investigated the time off golf (i.e. lost to injury) among injured golfers following their injury. Over half $(55.2 \%)$ of those injured reported taking time off both play and practice and a further $5 \%$ took time off either practice or play. Given that over $12 \%$ of golfers with injures had over 3 months off play or practice, and nearly one-quarter had over 6 weeks off, suggests that the severity of the average golf injury may be greater than generally acknowledged by the public.

According to this study, golfers over the age of 40 years had the highest risk of injury. Golfers in the 40 - 59-year and the 60 - 69-year age groups were over 5 times more likely to sustain an injury than golfers under the age of 20 years, 
TABLE III. Results summary from the multivariate analysis

\begin{tabular}{|c|c|c|c|c|}
\hline \multirow[b]{2}{*}{ Variable } & \multirow[b]{2}{*}{$p$-value } & \multirow{2}{*}{$\begin{array}{l}\operatorname{Exp}(B) \\
\text { i.e. OR }\end{array}$} & \multicolumn{2}{|c|}{$95.0 \% \mathrm{Cl}$ for true $\mathrm{OR}$} \\
\hline & & & Lower & Coefficient \\
\hline Age (0-20 baseline) & 0.011 & & & \\
\hline $20-29$ & 0.041 & 3.799 & 1.058 & 13.641 \\
\hline $30-39$ & 0.043 & 3.206 & 1.035 & 9.926 \\
\hline $40-59$ & 0.001 & 5.654 & 1.993 & 16.037 \\
\hline $60-69$ & 0.002 & 5.386 & 1.855 & 15.639 \\
\hline $70+$ & 0.009 & 4.364 & 1.448 & 13.146 \\
\hline No response & 0.686 & 1.455 & 0.236 & 8.952 \\
\hline Injuries in other activity (yes vs no) & 0.000 & 2.227 & 1.577 & 3.143 \\
\hline Club shafts (all steel baseline) & 0.055 & & & \\
\hline Steel irons/graphite woods & 0.007 & 1.761 & 1.171 & 2.649 \\
\hline All graphite & 0.034 & 1.569 & 1.036 & 2.376 \\
\hline Graphite irons/steel woods & 0.893 & 1.115 & 0.228 & 5.457 \\
\hline Wear glove ( $0=$ 'no' as baseline $)$ & 0.000 & & & \\
\hline Yes left hand & 0.002 & 1.737 & 1.216 & 2.483 \\
\hline Yes right hand & 0.043 & 1.688 & 1.017 & 2.802 \\
\hline Yes both hands & 0.000 & 5.139 & 2.258 & 11.698 \\
\hline Wear golf shoes ( $0=$ 'no' as baseline) & 0.082 & & & \\
\hline Yes/plastic spikes & 0.186 & 0.633 & 0.321 & 1.247 \\
\hline Yes/rubber ripples & 0.022 & 0.420 & 0.200 & 0.882 \\
\hline Yes/metal spikes & 0.552 & 0.771 & 0.328 & 1.814 \\
\hline No response & 0.128 & 0.418 & 0.136 & 1.285 \\
\hline Play practice warm-up range (yes vs no) & 0.001 & 1.627 & 1.228 & 2.154 \\
\hline $\begin{array}{l}\text { During week condition golf strength } \\
\text { (yes vs no) }\end{array}$ & 0.000 & 2.669 & 1.563 & 4.556 \\
\hline Chip-putt ( $\geq 1$ vs 0 - 1 ) & 0.237 & 1.280 & 0.850 & 1.926 \\
\hline $\begin{array}{l}\text { Frequency full shot practice } \\
\text { ( } 0-1 \text { as baseline) }\end{array}$ & 0.417 & & & \\
\hline $1-2$ & 0.131 & 1.385 & 0.908 & 2.114 \\
\hline $2-3$ & 0.251 & 1.500 & 0.750 & 2.997 \\
\hline $3+$ & 0.683 & 1.215 & 0.476 & 3.102 \\
\hline $\begin{array}{l}\text { Frequency game play } \\
\text { ( } 0-9 \text { holes as baseline) }\end{array}$ & 0.103 & & & \\
\hline $1-2$ rounds & 0.017 & 1.803 & 1.113 & 2.920 \\
\hline 3 rounds & 0.029 & 1.996 & 1.074 & 3.710 \\
\hline $4+$ rounds & 0.210 & 1.664 & 0.751 & 3.688 \\
\hline
\end{tabular}

with those over 70 years over 4 times more likely to injure themselves. The frequency of injury in golf may be due to the potential for a cumulative effect of injury as more than half of the injuries sustained were of insidious onset, and nearly half had been sustained previously (recurrent).

Those golfers who sustained a recurrent injury from participation and injury incurred in another sport / activity may have done so due to incomplete healing of a previous injury. Such mechanical inefficiency due to the previous injury may have resulted in compensatory muscle activity and secondary muscle activation, altering the efficiency of the golf swing.
This is a well-known injury factor, resulting in increased injury potential. A prospective cohort study could be used to further ascertain the relationship between swing mechanics and injury, using a representative sample of injury-free golfers.

Surprisingly, wearing golf gloves was associated with an increased risk of injury. Golf gloves are designed and used to improve the grip on the club, reducing the risk of slippage through greater friction between the club and the glove. However, variable grip pressure has been noted during the golf swing, with change in the forearm flexor force during the swing. ${ }^{5}$ Change in grip pressure and positioning of the 
forearm during the golf swing may lead to excessive cocontraction of the forearm extensors, potentially reducing the available range of motion to be exercised during the dynamic movement, thereby predisposing to increased eccentric muscle loading and injury. ${ }^{18}$ Variability in grip pressure may be related to injury rate and should be investigated further.

An accepted tenet in sports medicine is that a warm-up can minimise or reduce injury rates. ${ }^{26}$ However it is felt that whilst warm up prior to activity may be able to prevent muscular injuries, improper or excessive stretching and warming up can predispose to injury. ${ }^{23}$ Surprisingly, in this study range of motion exercises were associated with an increased risk of injury. Often this type of activity includes bouncing the body through the movement when the tissues are cold, akin to ballistic stretching. It is now believed that ballistic stretching (i.e. bouncing) is associated with increased injury rates. ${ }^{24}$ This predisposes the golfer who performs range of motion exercises to injury. Those performing air swings and hitting the ball as part of a warm-up process did not increase the risk of injury compared with the no warm-up group. In this cohort, golfers appeared to be more responsive to these types of warm-up activities. Further prospective investigation is required into the type of warm-up used (range of motion, air swings, hitting the ball, stretching), as well as how long and how often the warm-up exercises were performed prior to play in relation to injury generation.

Strength work, which was reported by respondents to be golf-specific, significantly increased the risk of injury, raising the question whether such activity benefits the golfer at all. As this survey was self-reporting of activity at a very cursory level, it is difficult to speculate why golf-related strengthening appeared to be associated with increased injury risk. It may not be causative at all and may constitute an aberrant statistical finding of association only. However, possible factors include overuse-related injuries and performing activities that are not conducive to improving the golf swing in terms of strength, speed or quality of movement; this may predispose players to injury due to the generation of incorrect muscle-firing patterns when compared with the ideal.

Univariate analysis found that the amount of chip-putt full shot practice and game play were significant in injury generation, with those who performed more activity in each group more likely to be associated with injury. However, after taking into account the potential for confounding, where the effect of one factor on an outcome is distorted by a second factor, it was found that play / practice habits were no longer significant.

A limitation of the study was the self-reporting nature of the survey and reliance on the responder to answer questions correctly. This is particularly the case when asking about injury mechanism and when the injury occurred. Whilst an aberrant swing as an injury mechanism was not identified by someone else (for example a golf professional), golfers have a basic concept of their golf swing. As such an individual would be able to determine that their golf-related injury was predisposed by their swing. In a similar way the golfer would be able to identify that the pain during his/her golf swing could be broadly categorised into the phases of the golf swing, viz. backswing, downswing and follow-through. The response rate achieved in this survey was $21 \%$. Compared with a $60 \%$ and over response rate, which is considered excellent, ${ }^{22}$ this is a low value. Many studies improve response rates by mailing multiple reminders / surveys to non-responders, which can increase response rates to over $70 \%$, ${ }^{1,25}$ but such studies generally involve smaller, discrete sample sizes and/ or very large budgets. It is likely that without large budgets, repeated national mail-out would be too costly. The accepted survey response rate for a single mail-out to a large sample size is $15-30 \%,{ }^{6,9,12,13,19}$ a range which the present study falls within.

The primary concern with a low response rate remains how representative the respondents are of the population being examined. ${ }^{21}$ However, a low response rate does not automatically imply that a non-representative sample has been selected. Researchers appear more concerned about the likelihood of bias in the collection of the sample rather than the specific sample size in isolation. ${ }^{1,25}$ Analysis of the latest Australian Bureau of Statistics data on sports participation and Australian Golf Union data on average handicaps show that the present study achieved a comparable maleto-female breakdown ratio $(82.2 \%$ vs $17.8 \%$ and $80.5 \%$ vs $19.5 \%)^{2}$ and comparable handicaps (male 18.1 and female 27.5 compared with 18.1 and 26.3). ${ }^{3}$ We conclude that our data appear to be reasonably representative of the general population of golfers. The above data will become baseline data for a prospective study that will determine the 1-year golf incidence rate in Australian amateur golfers.

\section{Conclusion}

This epidemiological investigation of golf injury found that the lower back, elbow and shoulder are the most commonly injured areas, and that these injuries were most likely caused by some part of the golf swing. Three-quarters of all injured golfers sought treatment for their ailment. Risk of injury during golfing varied according to age group, warm-up status, conditioning habits, whether the player wore a golf glove, and whether the golfer was injured in other sports/activities. Golf is one of the most popular sports played by the older population and the general age and golf participation rate are still rising. This makes it important to do further study on golf injury incidence, mechanism, management and other related issues, which will assist the golfing community to reduce the risk of injuries associated with golf.

\section{REFERENCES}

1. Asch DA, Jedrziewski MK, Christakis NA. Response rates to mail surveys published in medical journals. J Clin Epidemiol 1997; 50:1129-36.

2. Australian Bureau of Statistics. Participation In Sport And Physical Activities Australia 2002. Doc. No. 4177.0. Canberra, ACT: Australian Government, 2002

3. Australian Golf Union. AGU affiliated clubs membership statistics. May 2003. 
4. Batt ME. A survey of golf injuries in amateur golfers. Br J Sports Med 1992; 26: 63-5.

5. Budney DR, Bellow DG. Evaluation of golf club control by grip pressure measurement. In: Cochran AJ, ed. Proceedings of the World Scientific Congress of Golf Science and Golf I. St. Andrews, London, 9-13 July 1990: 30-35

6. Formoso G, Moja L, Nonino F, et al. Clinical evidence: a useful tool for promoting evidence-based practice? BMC Health Serv Res 2003; 3:24

7. Fradkin AJ, Cameron, PA, Gabbe BJ. Golf injuries-common and potentially avoidable. J Sci Med Sport 2005; 8: 163-70.

8. Gosheger G, Liem D, Ludwig K, Greshake O, Winkelmann W. Injuries and overuse syndromes in golf. Am J Sports Med 2003; 31: 438-43.

9. Greenwald R. Brief assessment of children's post-traumatic symptoms: Development and preliminary validation of parent and child scales. $R e-$ search on Social Work Practice 1999; 9:61-75.

10. Hosea TM, Gatt CJ. Back pain in golf. Clinics in Sports Medicine 1996; 15: $37-53$

11. Hosmer DW jun., Lemeshow S. Applied Logistic Regression. New York: Wiley, 1989

12. Massett HA, Greenup M, Ryan CE, Staples DA, Green NS, Maibach EW. Public perceptions about prematurity: a national survey. Am J Prev Med 2003; 24:120-7.

13. McCarroll, Retting AC, Shelbourne KD. Injuries in the amateur golfer. Physician and Sports Medicine 1990; 18: 122-6.

14. McCarroll JR, Gioe TJ. Professional golfers and the price they pay. Physician and Sports Medicine 1982; 10: 64-70.

15. McHardy A, Pollard H, Luo K. Golf injuries: A review of the literature. Sports
Med 2006; 36: 171-87

16.McHardy A, Pollard $\mathrm{H}$. Muscle activity during the golf swing. $\mathrm{Br} \mathrm{J}$ Sports Med 2005; 39: 799-804.

17. McHardy A, Pollard H, Bayley G. A comparison of the modern and classic golf swing: A clinician's perspective. South African Journal of Sports Medicine 2006;18:80-92.

18. Mogk JP, Keir PJ. The effects of posture on forearm muscle loading during gripping. Ergonomics 2003; 46: 956-75.

19. Nicholas J, Reidy M, Oleske D. An epidemiologic study of injury in golfers. Journal of Sport Rehabilitation 1998; 7: 112-21.

20. Pink M, Perry J, Jobe FW. Electromyographic analysis of the trunk in golfers. Am J Sports Med 1993; 21: 385-8.

21. Portney LG, Watkins MP. Foundations of Clinical Research: Applications to Practice. 2nd ed. New Jersey, NJ: Prentice Hall Health, 2000: 286.

22. Portney LG, Watkins MP. Foundations of Clinical Research: Applications to Practice. 2nd ed. New Jersey, NJ: Prentice Hall Health, 2000: 327.

23. Safran MR, Garrett WE, Seaber AV. The role of warm-up in muscular injury prevention. Am J Sports Med 1988; 16: 123-9.

24. Shrier I, Gossal K. Myths and truths of stretching; individualized recommendations for healthy muscles. Physician and Sports Medicine 2000; 28:

25. Stang A, Jockel $\mathrm{KH}$. Studies with low response proportions may be less biased than studies with high response proportions. Am J Epidemiol 2004; 159: $204-10$.

26. Strickler T, Malone T, Garrett WE. The effects of passive warming on muscle injury. Am J Sports Med 1990; 18: 141-5.

\title{
Hip Injuries, An Issue of Clinics in Sports Medicine
}

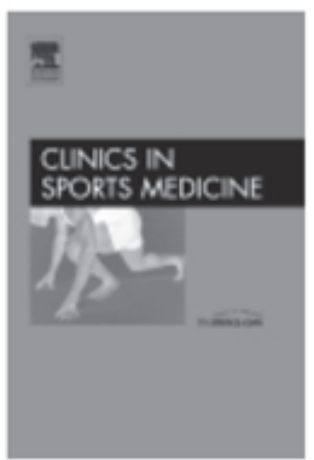

\section{To Order Please Contact:}

\author{
Health \& Medical Publishing Group \\ Private Bag X1, Pinelands, 7430 \\ Tel: 021 - 6578200 - Fax: 021- 6834509 \\ e-mail: carmena@hmpg.co.za / \\ brents@hmpg.co.za
}

By Mare J. Phillippon, MD; and Srino Bharam, MD

ISBN $1416035486 \cdot$ Hardback $\cdot 240$ Pages

Saunders . Published November 2006

\begin{abstract}
A source of stability and mobility, the hip can withstand a lot of abuse before becoming seriously damaged. When injury occurs no one is happy and movement is often stressful. Fixing and repairing the injured hip is covered in this issue. Chapters in this issue cover hip fractures, stress fractures, instability, impingement, rehabilitation, arthritis, tears, arthroscopy and the athletic hip. Key words: hip arthroscopy, acetabular labral tears, intraarticular injuries, pediatric athletic hip disorders, neuromuscular hip pathology, dislocation, subluxation instability, femoroacetabular impingement syndrome
\end{abstract}

